\title{
METODOLOGIAS SUBTERRÂNEAS DO PROCESSO CRIATIVO TERNURA
}

\section{UNDERGROUN METHODOLOGIES OF THE TERNURA CREATIVE PROCESS}

\author{
Raimundo Kleberson de Oliveira Benicio \\ kleberbeniciop@gmail.com \\ PPGAC/UFBA
}

\section{Cecília Lauritzen Jácome Campos}

cecilia.campos@urca.br

URCA

\section{Resumo:}

São apresentados diversos parâmetros metodológicos na tentativa de criar um "entre", dando abertura para clarificar estratégias por meio de rastros e reflexões, a partir de percepções relacionadas ao processo criativo Ternura (2016), cuja peça se insere como parte do repertório do grupo Trupe dos Pensantes (Crato/CE). Desta forma, as descrições ressaltam a importância dos estudos sobre o processo criativo, compreendendo como potência de pesquisa, evidenciando um percurso cartográfico e suas percepções com sua materialização.

Palavras-chave: Processo criativo, Pedagogia do Ator, Encenação Contemporânea.

\begin{abstract}
:
Several methodological parameters are presentes in na attempt to create a "between", opening to clarify strategies through traces and reflections, from perceptions related to the creative process Ternura (2016), whose piece is inserted as part of the repertoire of the Trupe dos Pensantes (Crato / CE) group. Thus, the descriptions underscore the importance of studies on the creative process, understanding as a research power, evidencing a cartographic path and its perceptions with its materialization.
\end{abstract}

Keywords: Creative process, Actor's Pedagogy, Contemporary Staging.

\section{Introdução/contexto que se insere estes escritos}

Este recorte apresenta uma parte da pesquisa do Trabalho de Conclusão de Curso intitulado "Os Múltiplos Olhares de Espectador: análises-reconstituições a partir da Trupe dos Pensantes", defendido na Universidade Regional do Cariri (URCA), se refere ao momento em que foram estruturadas por meio de uma cartografia enquanto ação (rastros processual do percurso metodológico), as metodologias desenvolvidas no espetáculo Ternura (2016) como parte de uma 
"análise-reconstituição" (PAVIS 2015), este último, alude ao contexto e extensão do processo criativo e das circunstâncias traçadas no seu desenvolvimento.

“Um dos deveres da análise é dar testemunho da emergência delas e de sua influência na formação do sentido (e dos sentidos). A escrita dramática, naquilo que tem de imediato e espontâneo, conserva às vezes um vestígio precioso delas" (PAVIS, 2015, p. 6). O vestígio que o ensaísta se refere a experiência da materialidade, aqui entendido como vetor de direcionamento para propor um descortinar das dificuldades e percepções geradas enquanto um olhar que está fora e ao mesmo tempo imerso como o(a) encenador(a). Para evitar um mal-entendido, clarifico que as tensões colocadas neste texto provem da experiência empírica, nosso objetivo não é chegar a uma pretensão genérica, mas provocativa em forma de descrições.

"A descrição do espetáculo navega sempre entre uma exigência totalizante de síntese e uma individualização empírica, entre ordem e caos, abstração e materialidade" (PAVIS, 2015, p.14). Dessa materialidade enquanto experiência compartilhada o(a) próprio encenador(a), atores e atrizes mergulham nos seus processos de reflexões para tensionar seus mecanismos metodológicos e busca pessoais que contribuíram para a solidificação do seu percurso criativo.

Portanto não pretendemos chegar a uma reflexão exaustiva, mas um possível retorno a experiência do encenador e do elenco. Desta forma, as descrições ressaltam a importância dos estudos sobre o processo criativo, compreendendo como potência de pesquisa evidenciando um percurso cartográfico enquanto ação de registro e suas percepções com a materialização do espetáculo Ternura.

\section{Contexto/grupo/partilhas iniciais}

Influenciado pelo arcabouço teórico do teatrólogo Augusto Boal, o grupo de teatro Trupe dos Pensantes surgiu em 2010, sob influência do Curso de Licenciatura em Teatro da Universidade Regional do Cariri (URCA), e possui em sua gênese a ideia de trabalho coletivo em uma perspectiva didático-social, ao propor e oferecer ações formativas livres em diferentes contextos formal e informal e públicos diversificados nas cidades do Crato, Juazeiro do Norte/CE.

A partir do processo criativo de Ternura (2016), são apresentadas várias perspectivas da recepção teatral que evidenciam algumas reflexões sobre sua atuação polimorfa, bem como 
diversas estratégias metodológicas que foram desenvolvidas na montagem do processo, aportando importantes contribuições de forma não sistêmica que podem servir de base para artistas e pesquisadoras que se interessem em problematizar as estratégias para a criação cênica.

O processo criativo de Ternura ocorreu durante um ano, tendo se iniciado em novembro de 2015 e estreado em novembro de 2016 na sede "Casa Ninho" do grupo Ninho de Teatro na cidade de Crato/CE. O tema central propulsor foi a violência à pessoa idosa.

Algumas ideias gerais pensadas inicialmente antes de entrar em sala de ensaio foram: Cena que volte no tempo (nesta era discutido sobre o cotidiano de forma poética a repetição de ações); Cena do pai e do filho; (discutia as relações entre pai e filho) Cena de/com distanciamento (falados algumas frases atuais sobre violência ou descaso a pessoa idosa); Cena do gravador; (gravações com depoimentos reais do elenco) Cena violência (discutia de forma poética a violência com simbologias).

\section{Construções dramatúrgicas textuais}

Algumas fontes inspiradoras para a concepção da dramaturgia foram lidos, por ordem cronológica: Liberdade, Liberdade de Millôr Fernandes e Flávio Rangel, o Manual de Enfretamento à Violência contra a Pessoa Idosa, as leis do Estatuto do Idoso, Esperando Godot e Fim de Jogo ou Fim de Partida de Samuel Beckett, Eis Artaud! de Florence Meredieu, Dissidente de Michel Vinaver, Ternura de Vinícius de Morais, Aos que virão depois de nós de Bertolt Brecht, O Mito de Pandora e Tempos Líquidos de Zygmunt Bauman. Foram assistidos, vídeos e documentários. Podese dizer que o texto Fim de Partida de Samuel Beckett é o propulsor para a versão final, pois dele provém o maior número de fragmentos que utilizamos. E também, recolhidas experiências através de uma caixa deixada no campus de Artes da URCA que serviram de estímulos para os atores elemento cênico para um quarto suspenso com fios de linho, possibilitando diversas interpretações. 
1. Cenário do Ternura. Músico: Davi Renan.

Acervo: autor.
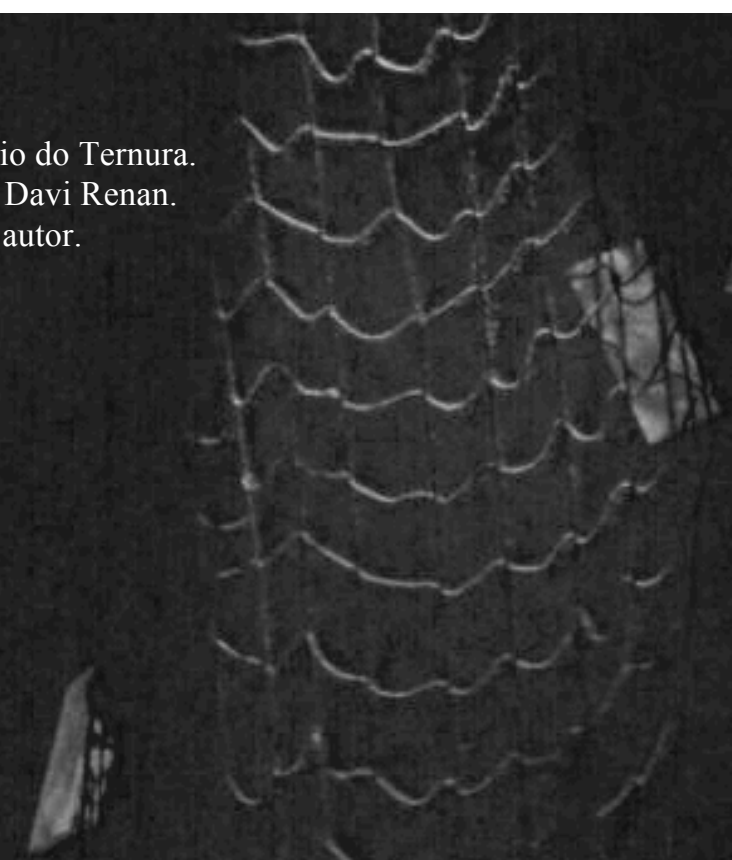


\section{Construções dramatúrgicas corporais/olhares enquanto encenador}

O processo foi iniciado com um caráter colaborativo, mas as oscilações de presenças e desistências de algumas pessoas ocasionaram uma tomada de decisão para construir uma dramaturgia apropriada com os que permaneceram: Matheus Maciel Cruz ${ }^{1}$ e Ailton Sinézio de Jesus $^{2}$, como atores, e pelo músico Davi Renan Oliveira Santos ${ }^{3}$.

Em meu diário, percebi um processo mais horizontal do que vertical, no qual foi possível detectar hierarquias estabelecidas entre os dois polos: direção e elenco.

A polimorfia dentro do processo criativo se insere em uma perspectiva de perceber em que medida a figura do(a) encenador(a) perpassa por situações deslizantes, em algumas ocasiões suas funções operam de forma mais determinante, e em outras, mais horizontal. Mesmo que eu tenha identificado tal horizontalidade, para os atores as duas relações estiveram presentes, como relatados por eles em entrevista realizadas em 2017:

Eu acho que foi colaborativo sim. Sei que boa parte das ideias do processo foram suas, mas nós sempre refletíamos e opinávamos. E várias ideias minhas também entraram para o processo, como as duas das músicas que eram utilizadas no espetáculo. Sempre me senti muito confortável para compartilhar o que eu achava que podia (JESUS, 2017).

Houve coisas da cena que você passou que eram só suas, apesar que eu acho que teve mais olhar de diretor do que de encenador. Ele não foi construído em conjunto, mas eu acho que conduzido por todos em algumas partes. Claro que tinha teu olhar em tudo, estava ali para dizer se estava bom ou ruim, mas creio que cada pessoa contribuiu para a construção do processo. Porque não trabalhamos sozinhos, você não estava com cena montada para mandar a gente fazer (CRUZ, 2017).

Essas duas relações abrangem outros panoramas que permitem pensar também na presença do encenador(a) dentro do processo criativo. Nos primeiros momentos do processo criativo as hierarquias entre ele/ela e o elenco são bem menos evidenciadas e são movidas por instâncias e estratégias criativas. Mesmo não estando inserido corporalmente nos exercícios que

1 Licenciando em Licenciatura em Teatro da URCA, desenvolve trabalhos como ator, músico e educador. Atualmente é integrante do grupo Trupe dos Pensantes exercendo a função de ator no espetáculo ternura, Alô Brasil! C@ntando Gonzaga.

2 Desenvolve trabalhos como ator/dançarino, músico/violoncelista e compositor. Ex-integrante do grupo Coletivo Dama Vermelha, Trupe dos Pensates e Núcleo de Investigação em Dança (Arruaça). Pesquisador no grupo Sétima de Cinema.

3 Licenciado em música pela Universidade Federal do Cariri (UFCA). 
contribuem para os territórios criativos, o(a) encenador(a), está exercitando e criando ao pensar nas imagens e modificações em que a cena sugere. Percebo que a participação, neste sentido, é mais interna do que externa, levando em consideração o processo sendo lapidado em sua mente a partir do que o elenco oferece como material.

Há encenadores(as) que conseguem construir seus percursos metodológicos sem nenhuma ideia de antemão iniciando seus processos na própria sala de ensaio. Ao longo desse processo pude verificar que funcionei a partir de ideias que permitiram inicialmente, buscar estratégias para um direcionar mais preciso. Acredito que neste tipo de criação, o incentivo proporciona um campo do imaginário expandido que perpassa por outras vivências do próprio encenador(a). Em relação a essas proporções, o pesquisador Antônio Araújo em seu texto $a$ encenação performativa (2008) discorre que a função do(a) diretor(a) ou encenador(a) perpassa por suas próprias histórias e experiências que irão influenciar em certa medida na escolha de seu percurso metodológico no qual "a encenação passa a ser, em certa medida, a encarnação, a 'miseenchair' do diretor' (ARAÚJO, 2008, p. 254).

O autor intensifica a ideia de vivência como material sugestivo para as estratégias que contribuem para uma seleção e percursos nas proposições dos exercícios ao levar em consideração sua própria percepção. A seguir serão descritos alguns dos exercícios do processo que foram evocados e redimensionados a partir da minha vivência como ator. As reflexões quanto à sua importância serão pensadas tendo em vista algumas respostas das entrevistas realizadas com os atores.

\section{Ressignificações dos exercícios (alguns)}

Seguíamos um roteiro inicial que era o alongamento em círculo, realizado ao mesmo tempo e em grupo. Em seguida, massagens, com a intenção de relaxamento e amenização de tensões corporais. Com a finalidade de reflexão acerca disso, uma das questões da entrevista realizada com os atores esteve relacionada às contribuições e eficácia dos exercícios na sua atuação. Segundo Ailton Jesus, a massagem contribuiu para a construção de interações e aproximações no grupo, o que não necessariamente implicou sua atuação:

Eu acho que eles contribuíram não necessariamente na minha atuação, mas nas interações com as outras pessoas que estavam no processo. Como nós tivemos 
desistências de pessoas, cada vez que entrava uma nova, tínhamos que nos adaptar a ela para dar continuidade às atividades. Eu acho que essa parte da massagem ajudou nisso, nessa interação com os outros atores que chegaram no processo. (JESUS, 2017).

Já Matheus Maciel acredita que além de contribuir para o relaxamento corporal, o momento da massagem foi, também, um direcionamento para a construção do seu personagem, o que implicou sua atuação:

Contribuiu porque ao mesmo tempo que relaxávamos você ia nos direcionando e dizendo 'vai pensando no personagem, vai pensando no tempo, vai pensando no que estava acontecendo naquela casa', então acho que, a partir dali, isso já ia relaxando e ao mesmo tempo nos fazendo pensar e deu certo. (CRUZ, 2017).

Fica evidente com os depoimentos que o exercício chegou diferentemente para cada um a partir do momento em que eles configuraram o sentido para si próprios, evidenciando um processo de seleção horizontal. A efemeridade do momento criativo impulsionou mais a preocupação de criar estratégias e conexão com as etapas do processo do que na própria transcrição dos exercícios que ia se metamorfoseando nos próprios encontros.

Isso ocasionou a criação de um diário que teve como intenção registrar não os exercícios, mas as sensações deles. Considero dessa forma, exercícios isolados e subterrâneos, os quais foram criados e adaptados para as especificidades somente dos encontros.

\section{I- Fixou foi!}

Um canudo é segurado pela boca de dois jogadores, eles devem prender a respiração e atravessar o espaço sem soltar o canudo. Nesse jogo pode-se alternar a quantidade de intervalos da respiração. Como por exemplo, atravessar segurando o ar por cinco segundos e assim por diante.

Nota: nesse jogo a respiração é trabalhada, bem como a relação em grupo e a base.

\section{II - Bastão em trânsito}

Os jogadores caminham pela sala e devem transportar um bastão. Ao pegá-lo, devem responder uma pergunta.

Nota: nesse exercício utilizamos o questionamento: o que você irá fazer quando envelhecer? Nesse caso, o intuito foi trazer questionamentos para criar estímulos para o processo. Além disso, foram trabalhados o ritmo, a relação em grupo, dentre outros. 


\section{III - Abraço questionador}

Os jogadores formam um círculo em volta de um jogador. O jogador do centro deve responder perguntas que os outros fazem enquanto olham diretamente para ele.

Nota: tais questionamentos foram mais uma vez relacionados ao universo da peça, como "quais doenças que os idosos podem ter"? "O que você faria se te abandonassem em um abrigo?", dentre muitas outras questões.

\section{IV - Caminhadas}

Como o próprio nome deduz, caminham pelo espaço investigando as acelerações e desacelerações do movimento.

Nota: nesse jogo foram inseridos alguns fragmentos textuais, de modo a investigar também suas alternâncias na pronúncia.

\section{V-Zonas Temporais}

O espaço deve ser dividido em tamanhos iguais, demarcados em forma de quadrado. Devem ser estabelecidas zonas temporais, ou seja, nesses determinados espaços devem conter uma descrição de tempo. Por exemplo: Zona 1: aceleração; Zona 2: desaceleração, Zona 3: tempo normal. O intuito é que quando o jogador passar por essa zona, deve criar imediatamente uma imagem e atravessá-la de acordo com o tempo demarcado.

Nota: esse jogo possibilitou a criação de diversas imagens que serviram como possível ferramenta para o corpo de seus personagens.

\section{VI -Petrificação de movimentos}

Caminhar pelo espaço imaginando que os músculos estão petrificados, alternando e fazendo uma flexão no joelho. Utiliza-se a alternância dos tempos, ora acelerado, ora desacelerado, ora normal.

Nota: tal procedimento serviu para explorar as delimitações de movimentos. Envolveu uma conexão com as delimitações que um corpo idoso pode ter. 


\section{VII - Falar para a parede}

Em pé, bem próximos da parede, os atores declamam fragmentos textuais de maneira diversa.

Nota: tal exercício possibilita que o ator/atriz tenha uma percepção mais ampliada da voz, bem como dos fragmentos.

Os dois últimos jogos foram significativos para o trabalho de construção de personagem para Ailton Jesus, como relatado por ele em entrevista:

O que eu acho que teve mais efeito foram os exercícios para criar tensões no corpo, porque era uma coisa que eu realmente precisava. Antes da estreia eu não estava achando meu corpo bom. Mas depois, várias pessoas vieram elogiar o meu corpo no espetáculo e aí foi quando eu percebi o quanto tinha surtido efeito. Mas também ajudou bastante, ficar dizendo as falas olhando para a parede, tentando encontrar entonações diferentes e tal, acho que foram os dois que eu senti mais efeito (JESUS, 2017).

Já para Matheus Maciel isso também ficou evidente quando ele relata que os exercícios que experimentou no processo do treinamento ajudou na sua criação do personagem. "os exercícios no treinamento me estimularam a criar o personagem" (CRUZ, 2017).

\section{Uma cenografia que se modifica}

A ideia de pensar em uma cenografia que estivesse o tempo todo vista pelo público e que se modificasse aos seus olhos foi uma proposta anterior à toda fase de sala de ensaio. A primeira parte do processo que pensei foram estas questões da cenografia.

Elas estavam relacionadas a pequenos bancos que, ao se unirem através da manipulação dos atores, formariam outro elemento cênico. Mas, foram abandonadas devido às necessidades que o processo foi exigindo.

Com isso, no processo de concepção da cena em sala de ensaio, procurei direcionar os atores para que eles tivessem consciência levando em consideração o caráter de transformação do objeto cênico e do espaço em arena que é considerado por Lehmann (2007) como Centrípeto, por ter a finalidade de estar próximo do público, a fim de tornar o evento cênico o mais orgânico possível. 
O objeto decisivo foi uma cadeira pensada para ser montada no decorrer do espetáculo, tornando-se elemento de suporte para as transições e marcações da peça como um todo. Ela pode ser dividida em duas partes, possibilitando que seja um banco e uma mesa, pois seu cano pode ser estendido a $1.20 \mathrm{~m}$. Quando montada, pode ser vista como uma cadeira de rodas.

Nas primeiras cenas ela está desmontada aludindo à mesa com seu cano esticado, em cima do objeto foi posto um porta-retrato. O outro apoio é colocado no chão e comporta o candeeiro. Esse mesmo apoio é usado metaforicamente para representar um caixão em outra cena, e por último, sua montagem toda ocorre nas proximidades finais da peça. Dessa forma, a cenografia foi um elemento que forneceu os acontecimentos, não apenas no sentido de temporalidade, mas também como possível gerador de metáforas isoladas inconscientemente no público.

2. Projeto de objeto cênico feito pelo artista e licenciado em Artes Visuais -URCA, ex-membro do grupo Trupe dos Pensantes Francisco Luiz Fernando Silva.

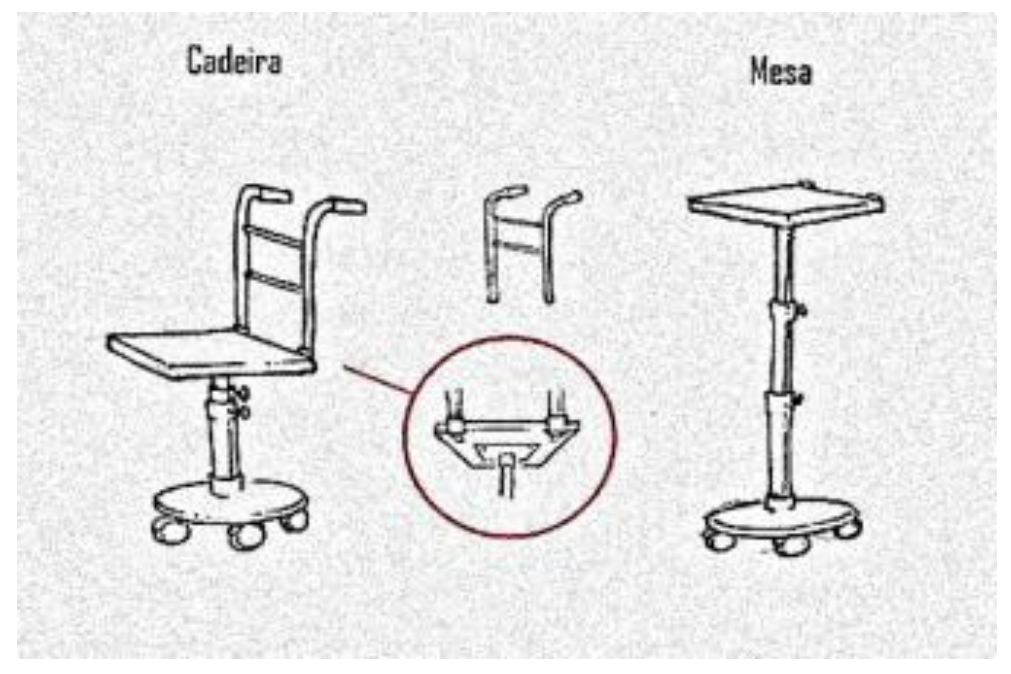




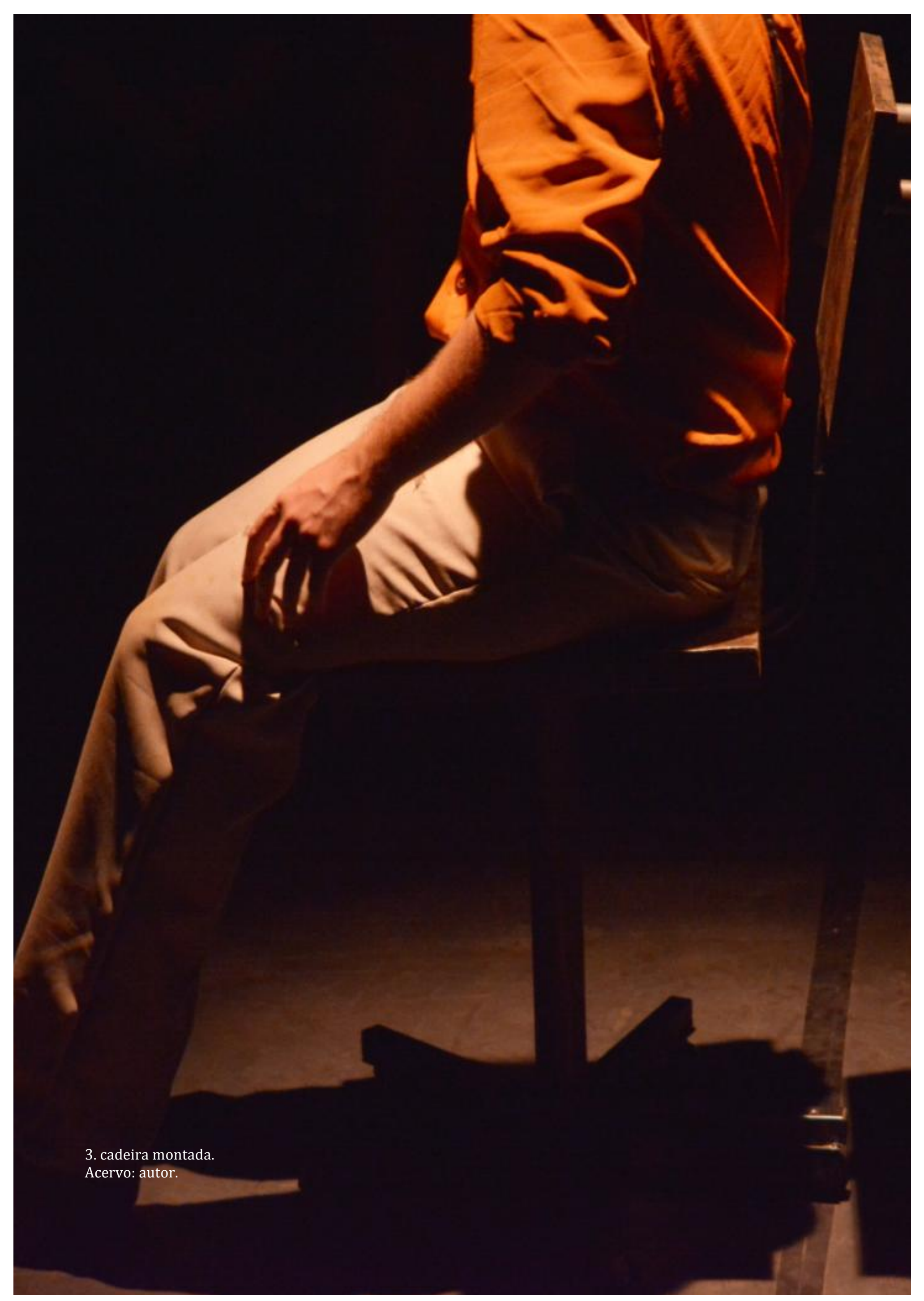

3. cadeira montada

Acervo: autor. 
4. cadeira montada.

Acervo: autor. 


\section{Uma peça tomada por cinza}

Existem momentos durante o percurso do processo que criativo, principalmente pelos desafios e tomadas de decisões que são tomadas, que o acaso aqui nesta experiência foi uma potência de acolhimento para o desenvolvimento das propostas cênicas e textuais. Escolhi Samuel Beckett por um motivo; sua capacidade de ser ilógico, indecifrável e suas obscuras incertezas, que proporcionam chaves interpretativas em cada fragmento lido.

As peças de Beckett possuem menos enredo que outras do Teatro do Absurdo porque apresentam uma inquirição sobre a condição humana, nas quais as imagens criadas pelo público ganham suas próprias interpretações. As personagens em seus textos tentam reconhecer sentido em si próprios, mas há também personagens que, de alguma forma, dependem um do outro para terem um equilíbrio quanto a sua sobrevivência no cotidiano, esses que Esslin denomina de "Complementares":

O contraste entre seus temperamentos dá origem a intermináveis implicâncias mútuas e muitas vezes leva à sugestão de que eles se deveriam separar. Entretanto, sendo naturezas complementares, eles são mutuamente dependentes e têm necessidade de ficar juntos. (ESSLIN, 1968, p. 41-42).

Essas possíveis características do absurdo estão presentes na dramaturgia do Ternura por conter, como dito anteriormente, diversos trechos da peça Fim de Partida. Tais elementos podem ser identificados não apenas em algumas passagens, mas nas cenas da peça. O que se pode falar sobre o contraste da cena são as oposições. Personagens que dificilmente se encontram de frente um para o outro, marcações que equilibram o preenchimento do espaço, personagens que dependem um do outro para se locomover, comer, marcam devidamente a maioria das cenas de Ternura.

As janelas delimitadas pela luz cênica preenchem o espaço proporcionando possíveis sensações de enclausuramento. A cena tomada por um cinza pronunciado no discurso do ator, potencializa e tenciona a trama. A música acompanha o ritmo das cenas que retrocedem criando algumas ilusões, aparentemente a sensação é de que todos os dias sempre acontecem as mesmas ações. 
5. cena janelas com ações complementares.

Acervo: autor. 


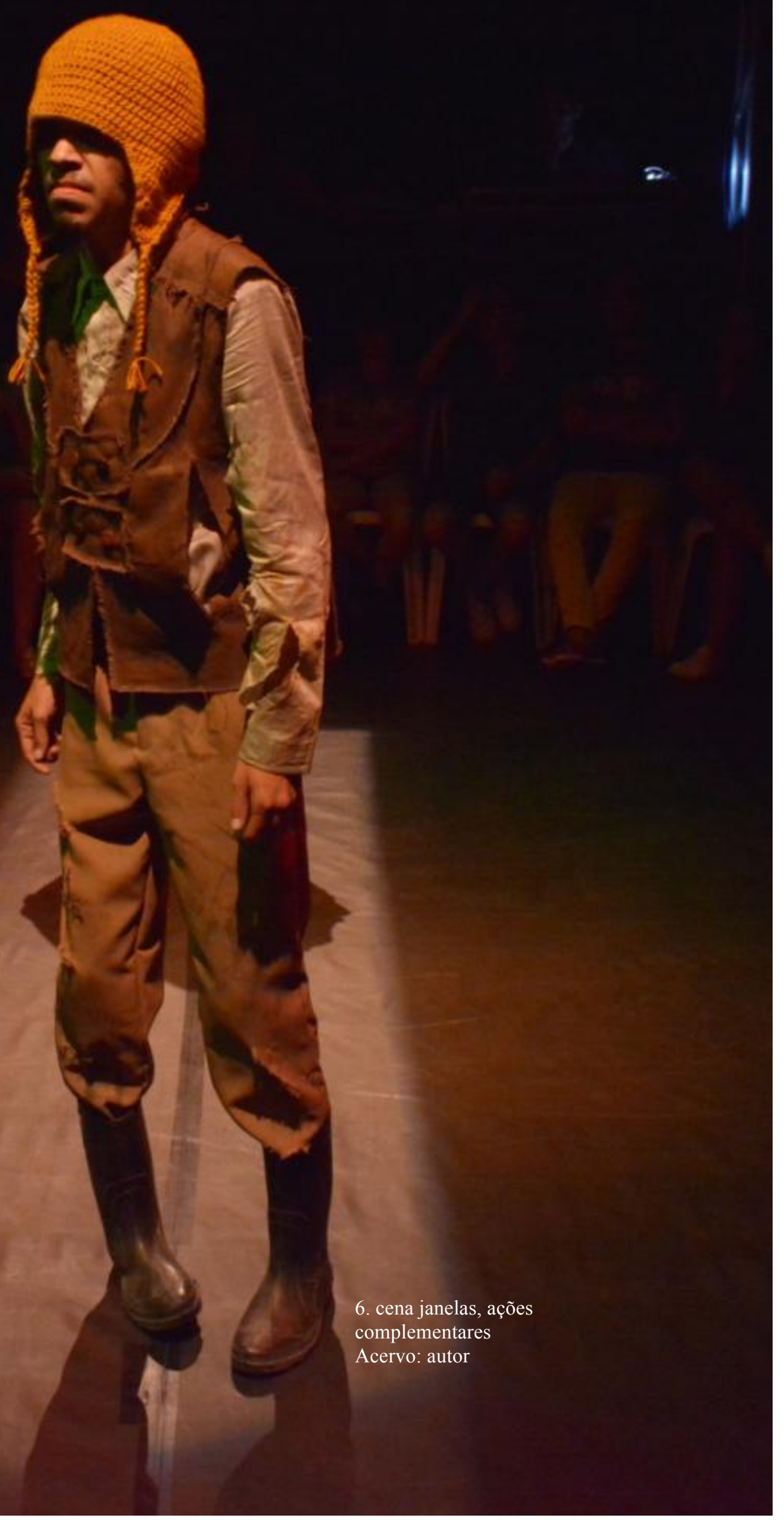


O processo criativo, dessa forma, parece ser um trânsito de acontecimentos inesperados, que são reorganizados pelo(a) encenador(a) em conjunto com o material que o elenco oferece, $\mathrm{O}$ que se está em jogo é a relação de algumas dificuldades que surgem, e obrigam-no a assumir um papel com maior decisão ou com proporções horizontal, e que podemos tentar ponderar sua operacionalidade polimorfa, levando em consideração sua atuação deslizante entre tomada de decisão, reorganização de material criado pelo elenco e o descarte dos mesmos para propor a materialização da cena.

As relações criativas operam em caminhos distintos que se complementam quando a cena se materializa. $\mathrm{O}(\mathrm{a})$ encenador(a) trabalha entre os dois espaços-tempos, tanto interiormente como externamente, auxiliando e incentivando o elenco para os caminhos necessários exigidos pelo processo criativo. Os rastros aqui expostos ressaltam a importância da construção de um mapa de ação, cujos registros permitem uma imersão processual que evidenciam os percursos elaborados como estratégias escolhidas.

As considerações aqui apontadas não se finalizam com pontos, mas com diversas reticências aguardando outros levantamentos de questões inacabadas ou não ainda discutidas pelo próprio tempo que dura o amadurecimento da experiência, percebi que a análisereconstituição colabora para possibilitar uma abertura aos diversos parâmetros de análises preciosas, muitas vezes, caótica e que perpassa o imaginário criativo de quem frui (encenador) e de quem materializa o processo (ator-atriz), análise reconfigurada como experiência compartilhada através de múltiplos olhares e diferentes formas que o processo criativo se consolida.

\section{Referências}

ARAÚJO, Antônio. A encenação Performativa. Sala Preta, São Paulo, v. 8, 2008. Disponível em: http://www.revistas.usp.br/salapreta/article/view/57375/60357. Acesso em: 18 out, 2018.

BECKETT, Samuel. Esperando Godot. Trad. Fábio de Souza Andrade. São Paulo: Cosac Naify, 2005.

Fim de Partida. Trad. Fábio de Souza Andrade. São Paulo: Cosac Naify, 2010.

BAUMAN, Zygmunt. Tempos líquidos. Tradução Carlos Alberto Medeiros. Rio de Janeiro: Jorge Zahar, 2007. 
BRASIL. Ministério da Saúde. Estatuto do Idoso. 1e ed. 2.a reimpr. - Brasília: Ministério da Saúde, 2003. Disponível em:

<http://www.saude.pr.gov.br/arquivos/File/pagina_saude_do_idoso/estatuto_do_idoso.pdf> . Acesso em 05 abr. 2015.

BRECHT, Bertolt. [s.t.;s.d.;s.a]. Disponível em:

<http://ciml.250x.com/archive/communists/brecht/spanish/bertolt_brecht_-_100_textos.pdf> . Acesso em 20 abr. 2015.

-- Aos que virão depois de nós (Gestus).Disponívem

em:<https://www.youtube.com/watch?v=cuucaQfluuo >. Acesso em: 23 abr. 2018.

BRASIL. Secretaria de Direitos Humanos da Presidência da República. Brasil: manual de enfrentamento à violência contra a pessoa idosa. É possível prevenir. É necessário superar. / Secretaria de Direitos Humanos da Presidência da República. Texto de Maria Cecília de Souza Minayo. Brasília: Secretaria de Direitos Humanos da Presidência da República, 2014.

CRUZ, Matheus Maciel. Entrevista semiestruturada, Crato/CE, 01 out 2017.

ESSLIN, Martin. O Teatro do Absurdo. Trad. Barbara Heliodora. Rio de Janeiro: Zahar Editores, 1968.

FERNANDES, Millôr; RANGEL, Flávio. Liberdade, liberdade. Porto Alegre: L\&PM, 2006.

JESUS, Ailton Sinézio de. Entrevista semiestruturada, Juazeiro do Norte/CE, 06 set. 2017.

LEHMANN, Hans-Thies. Teatro pós-dramático. Trad. Pedro Sussekind. São Paulo: Cosac Naify, 2007.

MORAIS, Vinicius de. Novos Poemas. Rio de Janeiro: José Olympio, 1938.

MEREDIEU, Florence. Eis Artaud. Trad. Isa Kopelman, São Paulo: Perspectiva, 2011.

PAVIS, Patrice. A análise dos espetáculos: teatro, mímica, dança, dança-teatro, cinema. Trad. Sérgio Sálvia. São Paulo: Perspectiva, 2015.

VINAVER, Michel. Dissidente. O Programa de Televisão. Trad. Catarina Sant'Anna. São Paulo: EDUSP. 2007.

Artigo submetido em 15/07/2019, e aceito em 26/11/2019. 